The philosopher and architects. Deconstruction of architectural axioms with effect from Derridean discourse

\section{| RESUMEN |}

El pensamiento del filósofo Jacques Derrida, denominado deconstrucción, se ha diseminado más allá de su propia disciplina e influido en aquellas que ha afectado. Pero no nos ocuparemos de todos sus planteamientos, sino de aquel que se interesa por la metafísica y sus intrínsecos sistemas de pares axiológicos. Igualmente, tampoco vamos a abordar todas las materias interesadas por su discurso, sino solo la arquitectura. Este escrito pretende identificar de qué modo sus propuestas han influido en dicha materia y si ha generado una revisión «crítica» o «deconstructivista» de algunos pares de opuestos axiomáticos de la arquitectura.

\footnotetext{
ABSTRACT |

Deconstruction, the thought of philosopher Jacques Derrida, has spread beyond its original discipline and has influenced those affected. However, we don't use the full extent of its proposals, only those related to the metaphysical and its axiological intrinsic pairs systems. Similarly, we will not deal with all matters concerned with Derrida's discourse, only architecture. This paper aims to identify how his proposals have influenced this matter and if they have generated a «critical» or «deconstructive» revision of some pairs of opposite architectural axiomatic
}

\title{
El filósofo y los arquitectos Deconstrucción de axiomas arquitectónicos a partir del discurso derrideano
}

\section{EL PENSAMIENTO DERRIDEANO MÁS ALLÁ DE LA FILOSOFÍA}

Es ampliamente reconocido que el pensamiento del filósofo argelino-francés Jacques Derrida denominado deconstrucción, ha atravesado los límites de su disciplina e influido en otras; él mismo lo admite a través de entrevistas y publicaciones. Efectivamente, sus planteamientos habían cobrado un gran interés más allá del "corpus filosófico», lo cual es consecuente con la posición del filósofo, quien insiste en provocar a la filosofía hacia nuevas jugadas, en las que ella no se reconozca ni siquiera a sí misma, a la vez que reexamine sus relaciones con otras disciplinas.

Pero sus planteamientos no solo habían cruzado fronteras disciplinarias sino también geográficas. Sin duda, la más importante de todas ellas es su conquista de los Estados Unidos, en 1966, cuando participa en el coloquio organizado por la Universidad Johns Hopkins de Baltimore. En dicha ocasión expuso por primera vez sus postulados al público académico estadounidense, iniciando así la deconstrucción en dicho país.

Para los años ochenta, sus planteamientos, que ya habían alcanzado un punto álgido tanto en Europa como en los Estados Unidos, comenzaron a despertar un creciente interés en diversas disciplinas estéticas, y más concretamente en la arquitectura. Un interés que en el verano de 1988, llevó al MoMA de Nueva York a organizar una muestra sobre la propuestas arquitectónicas afectadas por su discurso, las cuales a partir de entonces se reunieron bajo el epígrafe de Arquitectura deconstructivista.

A partir de los ochenta, también se intensifica el vínculo entre Derrida y la arquitectura; se contacta con el arquitecto franco-suizo Bernard Tschumi y el neoyorquino Peter Eisenman con quienes participa en sus respectivos proyectos para el parque de la Villete de París. Consecuencia de estos contactos surgieron varios escritos como Point de folle: Maintenant L'ARCHITECTURE, ¿̇POR QUÉ EISENMAN ESCRIBE TAN BUENOS LIBROS? O CHORAL WORK. A partir de entonces

* Arquitecto por la Universidad Nacional de Tucumán, Argentina; Máster en Filosofía por la Universidad Nacional de Educación a Distancia (UNED), España; Doctor Arquitecto Universidad Politécnica de Madrid; Doctorando en Filosofía de la Universidad Complutense de Madrid, España. (Tesis Doctoral en elaboración). Profesor invitado en la Facultad de Arquitectura de la Universidad Nacional de Tucumán, Argentina. Profesor invitado en la Escuela de Arquitectura de la Universidad Politécnica de Madrid, España. Profesor Asociado en la Escuela de Arquitectura y en la Facultad de Ciencias Sociales de la Universidad Alfonso X, El sabio de Madrid, España. 
se acrecentó su participación en numerosos debates y la publicación de sus escritos sobre la arquitectura: EL FILÓSOFO Y LOS ARQUITECTOS, LAS ARTES DEL ESPACIO, LO ILEGIBLE, LA METÁFORA aRQUITECTÓNICA, CAMBIOS DE ESCALA, IR DESPACIO, DISPERSIÓN DE VOCES, son algunos de ellos.

Por lo expuesto, se suele considerar a estos arquitectos como los únicos en cuyas obras este influjo derrideano es notable o al menos justificable. Sin embargo, no podemos negar que otros, tanto incluidos como excluidos en la muestra del MoMA, no hayan sido afectados por su discurso, porque como señala Eisenman, el período cultural estaba imbuido de la deconstrucción y, en cierta medida, el sustento teórico de estas formas arquitectónicas fueron los postulados derrideanos.

\section{PRECISIONES SOBRE EL PLANTEAMIENTO DE LA DECONSTRUCCIÓN}

Heredero de Nietzsche y Heidegger, Derrida se ocupa principalmente de la metafísica tradicional y su intrínseco sistema de pares axiológicos que la caracteriza. Unos pares de opuestos que el pensamiento occidental ha asumido y utilizado desde siempre como hombre/mujer, sujeto/objeto, verdad/error, moralidad/amoralidad, espíritu/materia, naturaleza/cultura, caucásico/negro, cristiano/ pagano, etcétera.

Los conceptos y categorías que la mente propone para acceder y comprender la realidad son luego organizados de tal manera por ella misma, que genera pares conceptuales como los mencionados para facilitar la comprensión de dicha realidad. Y son estos pares de opuestos los que Derrida somete a revisión, porque sostiene que en ellos, uno de los términos del par tiene prioridad (el primero/primario) marginando entonces al otro (el segundo/secundario). Afirma que todo el pensamiento occidental se organiza en base a opuestos binarios y que tras fijarse dicho sistema como válido, uno de los dos conceptos describe lo que es fundamental y es tratado como central o principal, condenando, marginando y minimizando sempiternamente al segundo.
Para subsanar esta situación, se podría recurrir a un juego del filósofo crítico, en el cual se tomaría partido por la instancia reprimida, pero de esta manera las contraposiciones quedarían en pie y el juego proseguiría infinitamente. Esto lleva a Derrida a rechazar las subversiones simples, que mantienen intacta la oposición y a proponer su «estrategia general de la deconstrucción», cuyo objetivo es encontrar y mostrar la articulación fundamental en que se funda tal contraposición para deconstruirla. No pretende el reemplazo de una jerarquía por otra dentro de la oposición, sino la puesta en cuestión radical, y con consecuencias ilimitadas, de todas las parejas de oposiciones, de toda lógica binaria y que esta resulte inestable infinitamente. Por ello, nunca se pone del lado de uno de los opuestos, sino que siempre adopta el lugar que los hace temblar a ambos, es decir, el lugar de lo diferente, lo différance o lo ausente que esconde tal oposición; los indecidibles. Estos actúan como unidades que no se dejan apresar en la oposición binaria y que, sin embargo, la habitan, resisten dentro de ella y la desorganizan.

Pero estas oposiciones de conceptos metafísicos no enfrentan solamente dos términos, sino que además generan un orden con una subordinación y una jerarquía, la cual posteriormente adquiere el carácter de centralidad. Por ello el planteamiento de Derrida, por un lado, cuestiona la jerarquía adquirida por uno de los dos elementos constitutivos del binomio y, por otro, replantea la jerarquía como idea de centralidad dominante.

Para ello no busca subvertir la jerarquía original de modo que el primer componente pase a ser el segundo, sino que propone un sistema donde la nueva jerarquía sea inestable y nos obligue a entregarnos al libre juego de los opuestos binarios dejando las jerarquías de lado y permitiendo que ambos componentes del par se muevan libremente sin jerarquías, estabilidades o fijaciones perpetuas.

Como consecuencia de ello el elemento jerárquico también pierde su posición dominante, privilegiada o central, lo cual también despierta interés en el filósofo. Así,
Derrida relativiza y desjerarquiza, con un innegable espíritu nietzscheano, las categorías y verdades absolutas. Por este motivo, cualquier afirmación del tipo «la desconstrucción es» automáticamente estaría errada, puesto que deconstruir suele referirse, entre otras estrategias, a una lectura que apunta a la ruptura del concepto único y central dominante. Una centralidad que de mantener su autoridad y privilegio, en el caso de los textos, por ejemplo, provocaría la coagulación del mismo; ante esto propone su diseminación.

Pero la idea de centralidad no solo afecta a los textos. Para Derrida todo el pensamiento occidental se basa en la idea de un centro, un origen, una verdad, una forma ideal, un Dios. Todas las culturas tienen sus propios símbolos religiosos centrales; cristianos, budistas, judías o musulmanes, los cuales intentan excluir a los otros y al hacerlo los ignoran o reprimen. Igualmente, en las sociedades en las que el hombre es la figura dominante, él es el centro, y la mujer es lo marginado. Se generan así, los opuestos binarios ya comentados, como dominantes/reprimidos, cristiano/judío o cristiano/pagano. Es por ello que para Derrida, todos los centros definen o fijan el juego de los opuestos binarios donde un término es central y el otro marginal. $Y$ es por ello que su estrategia deconstructiva reclama la carencia del mismo.

Ahora bien, ¿̇cómo se traduce este discurso en la Arquitectura? Ocupémonos de ello para ver hasta qué punto o de qué manera su pensamiento ha influido en lo que se ha denominado Arquitectura deconstructivista.

\section{LA DECONSTRUCCIÓN DE LOS OPUESTOS BINARIOS ARQUITECTÓNICOS}

El cuestionamiento de los opuestos binarios por parte de Derrida es, quizás, unos de los planteamientos que más repercusión ha tenido en la Arquitectura. De entre ellos hay dos que merecen especial atención y a los que algunos arquitectos deconstructivistas le han dedicado un lugar importante en sus proyectos. Nos referimos al binomio orden/caos y función/forma. 

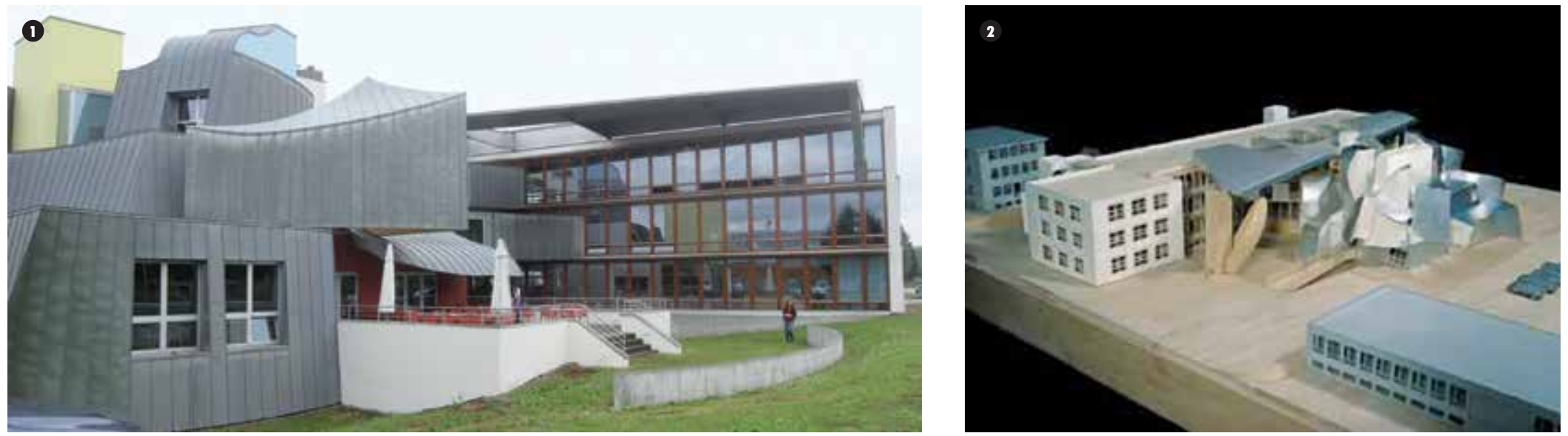

\section{ORDEN/CAOS}

Por diversos motivos, el caos estuvo históricamente desplazado y reprimido por la idea de orden en la composición arquitectónica; siempre fue considerado como la antítesis negativa del orden. Además, en los procesos del diseño siempre se han empleado lo que Eisenman denomina los «procedimientos de inclusión/exclusión»; una elección entre dos posibilidades: orden/caos. $Y$ en ese proceso siempre se favorece uno de ellos: el orden. Así, el orden se consolidó como sinónimo de buena arquitectura desde tiempos remotos; desde los griegos con la sección áurea y los órdenes, durante el Renacimiento por medio de las teorías renacentistas y en el Movimiento Moderno porque era sinónimo de claridad organizativa, un requisito previo para facilitar la producción en serie y generar una arquitectura eficiente y barata. Como explica Rem Koolhaas, los arquitectos del Movimiento Moderno fueron fatalmente atraídos por esa idea de orden y se sirvieron de las retículas, simetrías y de la antropometría para materializarlo. Sección áurea, órdenes, líneas reguladoras, Movimiento Moderno, funcionalismo y racionalismo están estrechamente vinculados al orden y, por tanto, son para los deconstructivistas como virus que atacan, entre otras cosas, a la imaginación y a la emoción, elementos básicos de la creatividad.

Conscientes de esa hegemonía, los deconstructivistas pretenden revalorizar el papel del caos en el proceso creativo. Pero no buscan con ello el detrimento o abolición de lo ordenado, puesto que también saben de los beneficios de este en una composición. Proponen que el orden no puede seguir regulando más la producción arquitectónica, sino que debe ser solo una alternativa dentro de la misma. Sostienen que ambos, orden y caos, son indispensables en toda composición; son dualidades inherentes e inevitables de un sistema. No los consideran dimensiones antitéticas, sino heterogeneidad en el seno de una homogeneidad. Como sugiere Antonio Escohotado «el pavoroso caos amenaza que cohesionó a tantas generaciones, es sencillamente el orden natural de las cosas».

Y esta dualidad contradictoria es lo que los deconstructivistas representan en sus obras. Lo podemos observar más precisamente en el trabajo de Frank Gehry, quien hace un proceso creativo a partir de esta relación de opuestos binarios. En un principio Gehry dispone lo ordenado y lo caótico por separado. En la Oficina de Vitra en Basilea un pabellón ordenado coexiste con una disposición caótica de volúmenes, pero ambas partes carecen de relación directa (FIguras 1 y 2). Un recurso que también encontramos en los Laboratorios de la Universidad de lowa o en el Museo Frederic Weisman de Minneapolis. Posteriormente, los componentes opuestos de esta dualidad comienzan una etapa de reconocimiento, de relación y penetración.
Así, lo caótico queda compenetrado con lo regular y ordenado, sin jerarquía alguna, como puede verse en el Museo Guggenheim Bilbao, donde los cuerpos regulares de piedra caliza se entrelazan con los volúmenes caóticos de titanio (FIgura 3). Un gesto que reaparece en el Centro Americano de París donde la parte regular dispuesta en forma de $\mathrm{L}$, referencia al ángulo recto y lo ordenado, se complementa con los volúmenes caóticos; una complementariedad acentuada por la uniformidad del material empleado (FIGURA 4). Finalmente, como una evolución más de la propuesta anterior y como apología de lo caótico, Gehry propone obras de formas plenamente desordenadas donde lo regular subyace sugerentemente. Ejemplo de ello son las Oficinas de la National-Nederlanden de Praga o el edificio central metálico del Centro Neve Zollhof de Düseldorff donde su dinamismo caótico se entrelaza con la sutil y ordenada disposición de las ventanas; la regularidad de sus formas y la iterabilidad en su disposición (FIGURA 5). Un gesto que se repite en numerosas obras más.

La Coop Himmelb(I)au también interpreta esta dualidad en su proyecto para la Fuderwerk III, donde la regularidad del pabellón industrial es combinada con una esquina caótica (FIGURA 6). Incluso, en el Ático del Bufete de abogados, la regularidad y el orden academicista de la fachada del edificio a intervenir son vinculados a las nuevas formas caóticas que ponen en 
3. Museo Guggenheim Bilbao, de Frank Gehry

4. Centro Americano en París, de Frank Gehry.

5. Centro Neve Zollhof en Düseldorf, de Frank Gehry.

6. Fuderwerk III, de la Coop Himmelb(I)au.
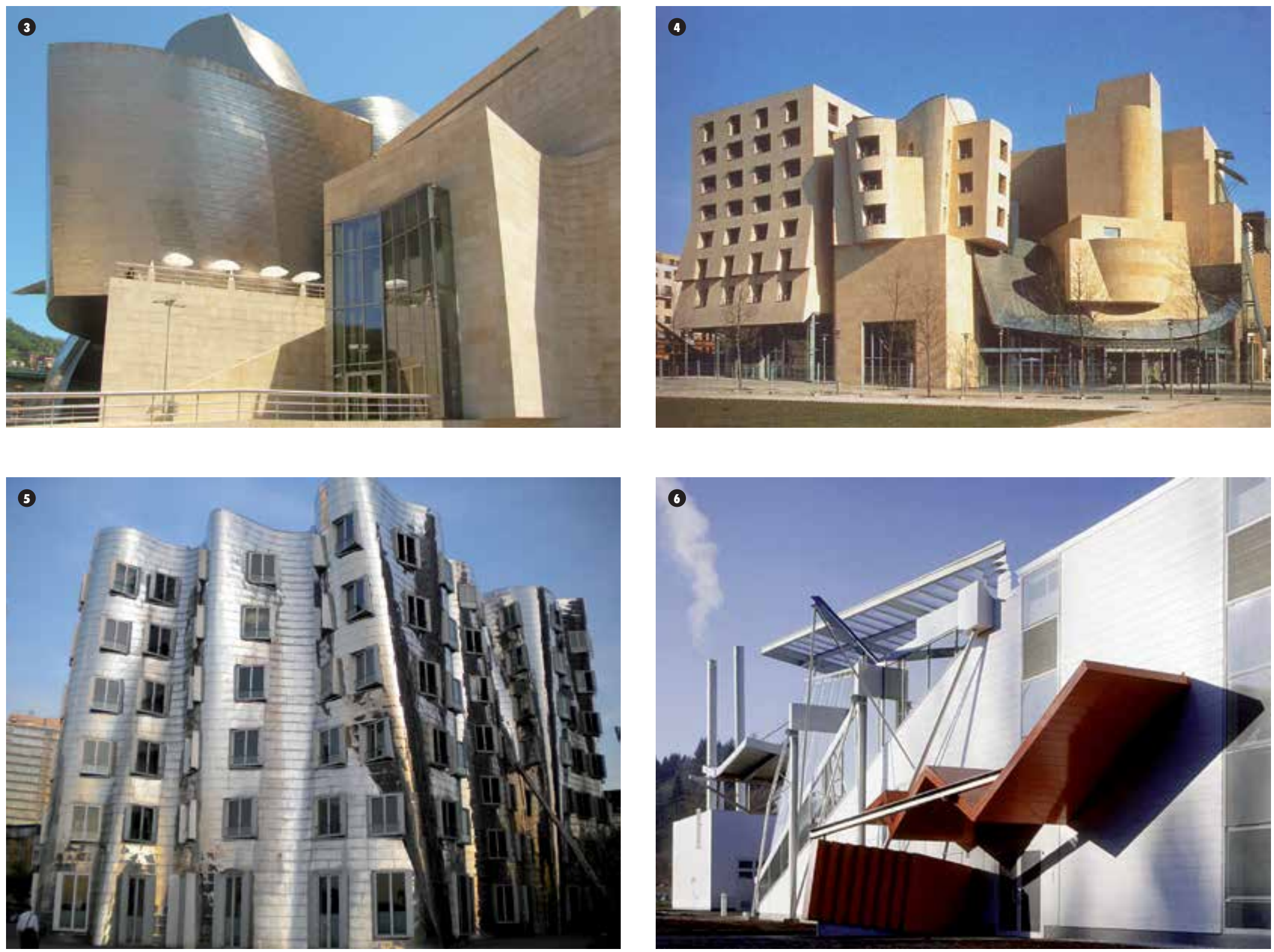

evidencia estos opuestos binarios orden/caos (Figura 7).

En este sentido, un aspecto importante a tener en cuenta era la materialización de estas formas caóticas. Se evitaría así no repetir lo acontecido con algunas propuestas de las vanguardias soviéticas de principio de siglo, las cuales, entre otras razones, no llegaron a materializarse por falta de la tecnología o conocimientos científicos adecuados. Esto también contribuyó a favorecer la elección de las formas ordenadas y cartesianas por su viabilidad y facilidad de ejecución.

Para poder materializar estas formas caóticos, los deconstructivista aprovecharon los avances científicos, los cuales durante el siglo xx, y en especial en las últimas décadas, fueron numerosos, espectaculares e inesperados.
De entre ellos, tres tuvieron gran repercusión: la teoría del caos, la geometría fractal y el desarrollo informático.

La teoría del caos había dejado de ser solo una teoría científica para devenir una metáfora artística que tenía mucho más que ver con la estética que con la ciencia. Consecuentes con ella, estos arquitectos consideran la anarquía como algo inherente al proceso creativo. Como 


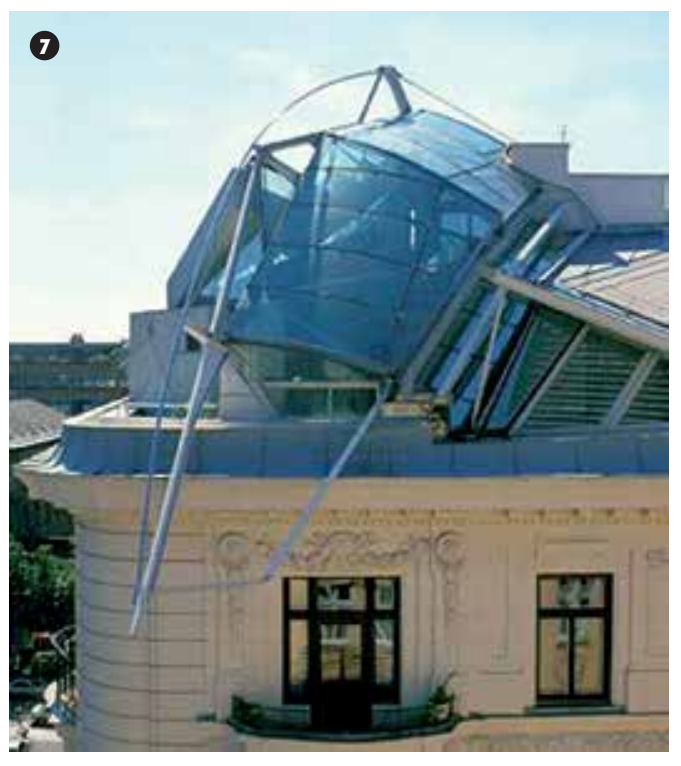

explica Paul Válery el «desorden es esencial para la «creación»».

Por otra parte, Benoit Mandelbrot proponía, en 1975, la geometría fractal como una geometría más afín al mundo físico que la euclidiana. Para Mandelbrot la geometría de la naturaleza -ríos, costas, árboles- es caótica y estaba mal representada por las formas de Euclides: triángulo, rectas, círculos, etc. Esta geometría fractal permitió redefinir las superficies topológicas o topográficas de los nuevos objetos arquitectónicos irregulares deconstructivistas, ratificando así lo que Mandelbrot sostenía: «el desarrollo más ampliamente constatado y el más inesperado no ha sido de carácter científico, sino puramente estético».

\section{FUNCIÓN/FORMA}

El segundo binomio de opuestos a destacar es el de la función/forma. Estas propuestas cuestionan la arraigada idea de que la forma deba estar sometida por la función y, por ende, la sentencia de Sullivan: «la forma sigue a la función». Incluso algunos sugirieron lemas para contrarrestarlo, como el de Wigley, La forma no sigue a la función, sino a la deformación, o el de Tschumi, La forma sigue a la fantasía. Al respecto, Eisenman recuerda que la arquitectura del siglo XX ha estado subordinada y legitimada por leyes como la de la utilidad. Para estos arquitectos la función no debe subordinar los aspectos compositivos o tectónicos de la arquitectura, y abogan por una libertad formal. Pretenden revalorizar el papel de la forma arquitectónica. Javier Maderuelo sostiene que «la arquitectura se ha consolidado en este siglo como un arte eminentemente funcional, en el sentido más utilitario del término, al extremo de haber olvidado las demás características, especialmente de que la arquitectura es una de las Bellas Artes».

No obstante, y al igual que ocurría con el binomio orden/caos, estos arquitectos son conscientes de la importancia de lo funcional en el proyecto y así lo expresa Gehry cuando dice: "Como arquitecto puedes hacer formas maravillosas, pero luego tienes que perforarlas en función de su uso interior. Hay algo muy determinante en la cualidad de los edificios como recintos, como contenedores de un programa».

Lo que proponen estos arquitectos es despertar del sueño funcionalista. Buscan que la forma no se subordine a la función, comience a cobrar presencia y deje de estar subordinada; que la forma se vuelva autónoma, en un objetivo de trabajo y no en una consecuencia del mismo. Lo formal en la arquitectura no debe reprimirse, puesto que, como señala Maderuelo: «la forma ha permanecido siempre unida a la naturaleza de la arquitectura desde sus primeras manifestaciones».

Incluso, la recuperación de la cualidad formal de las obras de estos arquitectos acercó sus propuestas al calificativo de escultórica, una andadura ya iniciada durante los años cincuenta. Un interés hacia la escultura que por estos años habían demostrado numerosos arquitectos, en especial por las obras de Henry Moore y Jean Arp. Esta influencia puede reconocerse en los trabajo de Gehry, por ejemplo, en los cuales han tenido gran repercusión las propuestas del escultor Wolfgang Luy, caracterizadas por el uso de fragmentos semicirculares de entarimados de madera.

En este sentido, es de destacar, y como también señala Charles Jencks, el interés que han demostrado Gehry y Zaha Hadid por las formas curvas. Estas también estuvieron bastante relegadas en el siglo Xx por las formas ortogonales, especialmente con el Movimiento Moderno. La línea curva, desterrada de la arquitectura como conformadora de espacios desde la implantación del neoplasticismo, va a reaparecer a finales de los años cincuenta con las propuestas de Félix Candela, NotreDame-du-Haut de Ronchamp o el Museo Guggenheim de Nueva York, y a finales de los ochenta con las propuestas deconstructivistas.

Por último, es importante señalar que este interés por resaltar el aspecto formal de la arquitectura se funda en un intento por recuperar el carácter artístico de la disciplina. El valor de la arquitectura ya no reside en su poder de redención social o de transformación de procesos productivos, sino en su poder de comunicación como objeto cultural. El significado, y no la reforma de las instituciones, es ahora otro de los objetivos de esta forma arquitectónica.

\section{ARQUITECTURA DES-CENTRALIZADA Y ANTIJERÁRQUICA}

El cuestionamiento de la centralidad, a partir de la revisión de los opuestos binarios, es otro de los aspectos del pensamiento derrideano que ha tenido su extrapolación en la arquitectura deconstructivista

El centro y la centralidad, patrimonio único de la arquitectura, son superados plenamente por la ausencia de límites concretos, de contornos determinados en las formas deconstructivas, puesto que, si no hay límites o contornos claros, no se pueden establecer centros precisos. Una pérdida de la centralidad que caracteriza tanto a los proyectos como al diseño de mobiliarios, como ocurre en el sillón Red sofa de Hadid (Figura 8). 
8. Sillón Red sofa, de Zaha Hadid.

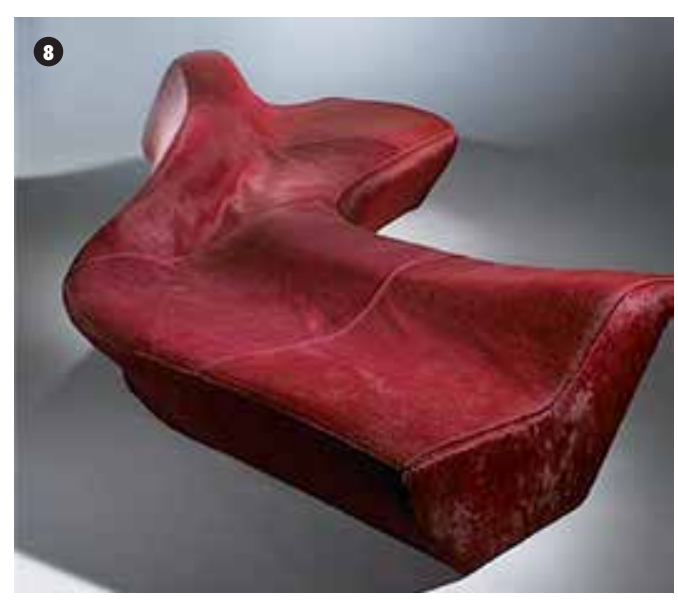

No obstante, hay diferentes interpretaciones al respecto. Como explica el propio Derrida sobre la obra de Eisenman, para evitar que exista un solo origen o un solo centro, el arquitecto imagina sus proyectos como el resultado de la superposición de una multiplicidad de capas, de estratos que pueden parecerse a estratos de memorias. El conjunto es una especie de palimpsesto, donde capas de proyectos se superponen, sin que haya uno que sea más fundamental o más fundador que el otro. Al poseer cada capa su centro, se produce, por la superposición, una multiplicidad de los mismos desjerarquizando al único.

Otro recurso que estos arquitectos emplean para transponer el discurso derrideano a sus proyectos son las retículas, por el carácter descentralizado de las mismas, las cuales además, incluyen el concepto derrideano de lo antiierárquico. La retícula distribuye el espacio y organiza lo que contiene en cada escaque, de tal modo que ningún elemento está situado en posición de dominar sobre los otros. En el espacio reticular el centro desaparece; no hay ninguno manifiesto y por ende ningún elemento jerárquico ni jerarquizado.

\section{CONCLUSIÓN: ¿CRÍTICA O DECONSTRUCCIÓN?}

Hasta aquí hemos expuesto los postulados derrideanos que despiertan interés en la
Arquitectura, sus influencias en la misma y el modo en que se transfieren de una disciplina a otra. Pero de entre los numerosos planteamientos del filósofo hemos hecho hincapié en aquellos que se ocupan principalmente de la metafísica tradicional y su inherente sistema de pares de opuestos axiológicos.

Sin embargo, esta revisión de principios, axiomas $\mathrm{u}$ opuestos binarios inherentes a la composición arquitectónica partiendo del discurso derrideano, en reiteradas ocasiones se ha interpretado como una revisión crítica de los mismos. En este sentido haremos una aclaración, que a su vez servirá de cierre del presente opúsculo.

Pese a que suele referirse a la deconstrucción como un «método de análisis crítico» esta no lo es: así lo aclara Derrida. No es un juicio valorativo, una decisión que se establece a partir de una serie de primacías y de jerarquías. No es una operación negativa, nihilista o escéptica, sino un movimiento afirmativo. Su modelo, no es un juicio determinante, sino el reflexivo. Derrida es preciso en esto cuando sostiene que la «deconstrucción no debe confundirse con un análisis o con una crítica», puesto que, como esta pretende siempre, por medio de un juicio discernir y decidir lo que es y lo que no es, lo que vale y lo que no vale, lo verdadero y lo falso, lo bello y lo feo, es decir, decidir a favor de uno de dos opuestos. En cambio, la deconstrucción se caracteriza por la búsqueda de lo indecidible, que muestra que «la decisión entre dos vías opuestas queda suspendida». Y es esa indecibilidad, intersticial entre dos opuestos binarios la que abre el camino de la diffèrance, de lo diferente siempre cohibido, para que afloren todas las posibilidades de expresión y manifestación que dicho objeto alberga reprimidas.

\section{REFERENCIAS BIBLIOGRÁFICAS}

Arnheim, R. El poder del Centro. Estudio sobre la composición en las Artes Visuales. Madrid: Akal, 2001
Cejka, J. Tendencias de la arquitectura contemporánea. Barcelona: Gustavo Gili, 1996.

Derrida, J. No escribo sin luz artificial. Madrid: Cuatro Ediciones, 1999.

Derrida, J. y Bennington, G. Jacques Derrida. Madrid: Cátedra, 1994

Derrida, J. y Eisenman, P. Chora L Works. Nueva York: Monacelli Press, 1997.

Derrida, J., Tschumi, B. y Vidler, A. Bernard Tschumi. La Casa Vide: La Villette. Londres: Architectural Association, 1986

Eisenman, P. El fin de lo clásico: el fin del comienzo, el fin del fin. ArquitecturasBis 1984; 48:28-36.

Eisenman, P. Procesos de lo intersticial. Notas sobre la idea de lo maquínico de Zaera Polo. El Croquis 1997; 83:21-35

Escohotado, A. Caos y orden. Madrid: Espasa Calpe, 1999

Ferraris, M. Introducción a Derrida. Buenos Aires: Amorrortu, 2006

Galard, J. La obra exapropiada. Derrida y las artes visuales. Escritura e imagen 2006; 2:57-70.

Graafland, A. y Haan, J. de. Conversación con Rem Koolhaas. Pasajes Arquitectura y Crítica 2000; 15:32-39

Johnson, P. y Wigley, M. Arquitectura deconstructivista. Barcelona: Gustavo Gili, 1988.

Krieger, P. La deconstrucción de Jacques Derrida (1930-2004). Anales del Instituto de Investigaciones Estéticas 2004; 84:179-88.

Maderuelo, J. El espacio raptado. Interferencias entre arquitectura y escultura. Madrid: Mondadori, 1990.

Mandelbrot, B. Los objetos fractales. Forma, azar y dimensión. Barcelona: Tusquets, 2000.

Peretti Peñaranda, C. de. Deconstrucción(es): una pluralidad singular. Volubilis. Revista de Pensamiento. ¿̇Qué postmodernidad? 1995 $1: 15-27$.

Peretti Peñaranda, C. de. Jacques Derrida. Texto y deconstrucción. Barcelona: Anthropos, 1989.

Peretti Peñaranda, C. de. y Vidarte, F. Jacques Derrida (1930). Madrid: Ediciones del Orto, 1998.

Powel, J. y Howell, V. Derrida para principiantes. Buenos Aires: Era Naciente, 2004.

Valery, P. Teoría poética y estética. Madrid: Visor, 1990

Zaera-Polo, A. Una conversación con Peter Eisenman. El Croquis 1995; 83:6-20.

Zaera-Polo, A. Conversaciones con Frank Gehry. El Croquis 1995; 74/75:6-37 